\title{
Investigation Of Soil Structure Interaction Problem For A Masonry Building
}

\author{
${ }^{1}$ Asuman Işıl Çarhoğlu and *2Pınar Usta \\ ${ }^{12}$ Faculty of Engineering, Department of Civil Engineering Suleyman Demirel University, Turkey \\ ${ }^{*}{ }^{2}$ Faculty of Technology, Department of Civil Engineering Applied Science University of Isparta, Turkey
}

\begin{abstract}
:
When the behaviors of the structures under the earthquake effect are examined, they are assumed as fixed foundation. Since the differentiation of the soil characteristics effects the behavior of the structures, the soil structure interaction should be taken into account in the earthquake analyzes. The main objective of this research is to examine the soil structure interaction. In this research, the masonry structure with two stories constructed from the stone material is handled. In addition to this, the soil is taken into consideration as sand, clay, rock, and fixed support. The masonry structure with two stories and the different soil layers have been modeledthree-dimensionally by with SAP 2000 program. In the scope of research, Kobe ground motion data was applied to the soil-masonry structure systems by using time history method in the analysis.
\end{abstract}

Keywords:Masonry structure, the soil structure interaction, time history analysis,

\section{Introduction}

Soil-structure interaction is an interdisciplinary field of endeavor which lies at the intersection of soil and structural mechanics, soil and structural dynamics, earthquake engineering, geophysics and geomechanics, material science, computational and numerical methods, and diverse other technical disciplines. Its origins trace back to the late 19th century, evolved and matured gradually in the ensuing decades and during the first half of the 20th century, and progressed rapidly in the second half stimulated mainly by the needs of the nuclear power and offshore industries, by the debut of powerful computers and simulation tools such as finite elements, and by the needs for improvements in seismic safety[1,2].

Research in the structural engineering, the structures are usually assumed to be fixed support by neglecting the effect of soil. In this case, it is assumed that there is not displacement on the foundation. However, the collapses and rotations occur on the base during the earthquake. In this case, the structure and soil interact with each other $[3,4]$.

The effect of coupling between soil and structure. As well known, SSI produces two important effects from the structural viewpoint:

- elongation of the fundamental vibration period of the coupled system compared to the fixed-base scheme;

*Corresponding author: Address: Faculty of Engineering, Department of Civil Engineering Suleyman Demirel 
- increase in damping due to the energy dissipation through the foundation soil (radiation damping).

Because of these effects, SSI is usually considered beneficial for the structural analysis since it is expected to reduce the seismic action on the building [5].

Many important masonry structures, build by using stone, brick, and adobe, have been built in seismic areas. On the 23rd and 9th of November 2011, it was determined that many masonry buildings were damaged during the Van earthquake, which was 7.2 and 5.6 in size [6]. It is necessary to known the earthquake behaviors of the masonry structures in terms of the sustainability of them. For this reason, determination of the behavior of the construction built on soft and medium hard soils, is quite important.

When the structures are exposed to the earthquake loads, the vibrations on the soil and structure are occurred. When the soil and structure are oscillated in the same period, the resonance and the damages on the structure occur [7-8]. Multistory buildings and low-rise buildings should be constructed on the hard soil and the soft soil, respectively. Even the low-rise buildings on the soft soils are built, the interaction between the soil and structure is great importance [9-10]. According to the ground motion records taken from the same areas, it is seen that the results obtained from the soils, which have buildings and without buildings, are different. This difference shows that the building affects the soil [4-11-12]. The viscous boundary condition is applied to the boundary surfaces of the soils In order to apply the viscous boundary condition, the soil is assumed as isotropic and linear elastic. At the same time, the viscous conditions should be formed in the remote area from the structure [7-13].

Structure-soil-structure interaction (SSSI), just put forward in recent decades, means the dynamic interaction problem among the multi-structures system through soil ground. It is an interdisciplinary field of endeavor, which lies at the intersection of soil and structural mechanics, soil and structural dynamics, earthquake engineering, geophysics and geomechanics, materials science, computational and numerical methods, and diverse other technical disciplines. With the successful outcome about SSI, various kinds of theoretical methods and experimental installations are used to promote the study of SSSI [2-14].

Many studies have been made on the interaction of soil-structure. Elmas M., (1997) examined the interaction between soil-structure by using finite element methods and elastic springs [15]. Gaikwad M. V., (2015). considered a building frame and different soil types. Soil types deathwith are soft, medium and hard. They have performed analysis by using the ANSYS program [16]. Karabörk et al., (2005) have examined the different structure models which have different soil conditions. They have used time history analysis method by using SAP 2000 program [4]. Karacaet al.,(2007) have made the calculation of the coefficient of soil reaction and then, have determined the values of the moment and shear force by using the analytical and finite element methods [17]. Wang et al, (2017) have used ANSYS finite element program to further developed and enhanced for calculation in frequency domain, in which hysteretic damping can be considered for both the soil and the structures [2]. Garip Z.Ş, (2017) have examined concrete 
structures built on the soft and hard soils considering the different story numbers and story heights. Time history analysis method was applied using SAP 2000 program [9]. Vicencio and Alexander, (2018) have evaluated the effect of Structure-Soil-Structure Interaction (SSSI) between two buildings given different parameters of the buildings, inter-building spacing, and soil type [18].

\section{Materials and Method}

Within the scope of this study, the interaction between masonry structure and soil have been examined. The dimensions of the masonry structure is $14 \times 11$ square meter $\left(\mathrm{m}^{2}\right)$ and the height is $3 \mathrm{~m}$. The model of the masonry structure is shown in Figure 1. The construction of the masonry structure is used as stone. The dimension of soil is $45 \times 40 \times 20 \mathrm{~m} 2 \mathrm{In}$ the foundation, $2 \mathrm{~m}$ amplification is taken into account.

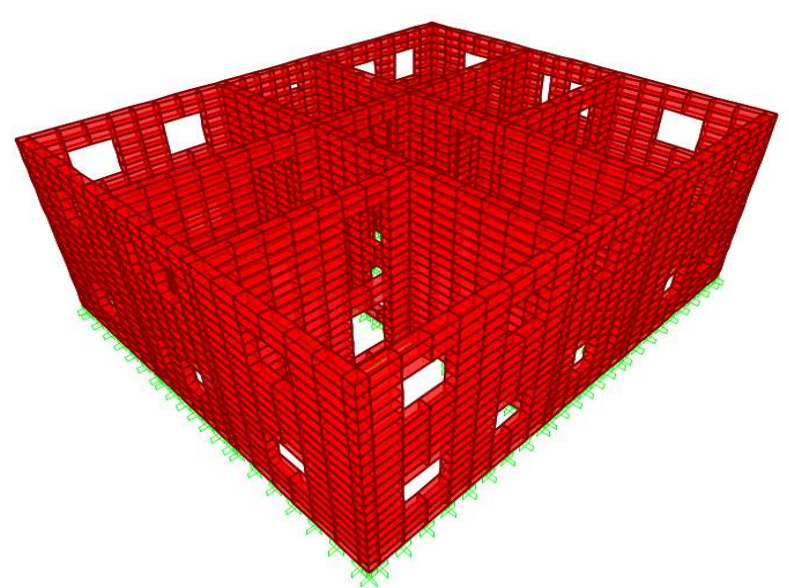

Figure 1.The model of the masonry structure

The masonry structure and soil were modeled with finite elements method by using SAP 2000 program and compared by considering the different soil layers. Solid element was used in the model. There is a foundation whose thickness is $1 \mathrm{~m}$ between soil and masonry structure.. While the masonry structure was designed as stone material, the soil layers were designed as sand, clay, and rock. The material properties of soil and masonry structures are shown in Table 1 and Table2, respectively. The models of masonry structure and soil layers are shown in Figure1.

Table 1.The material properties of soil

Material Modulus of Elasticity $\left(\mathrm{KN} / \mathrm{m}^{2}\right) \quad$ Unit volume weight $\left(\mathrm{kN} / \mathrm{m}^{3}\right) \quad$ Poisson Ratio

\begin{tabular}{l|l|l|l|}
\hline Sand & 50000 & 20 & 0.3
\end{tabular}




\begin{tabular}{|l|c|c|c|}
\hline Clay & 25000 & 19 & 0.3 \\
\hline Rock & 50000000 & 26 & 0.28 \\
\hline
\end{tabular}

Table 2.The material properties of the masonry structure

\section{Material Modulus of Elasticity (Mpa) Unit volume weight Poisson Ratio}

\begin{tabular}{|l|l|l|l|} 
& $\mathbf{K g} / \mathbf{m}^{\mathbf{3}}$ & \\
\hline Stone & 26000 & 2500 & 0.2 \\
\hline
\end{tabular}

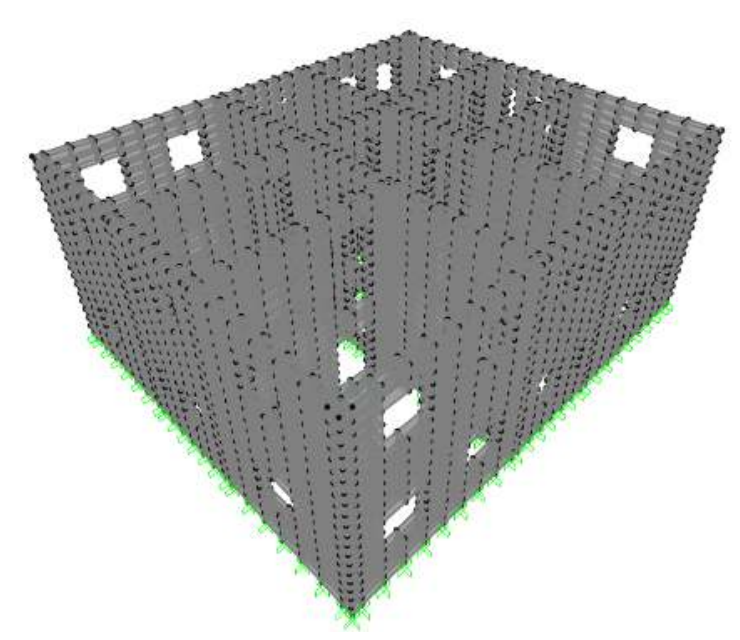

a) Model1(Fixed Support)

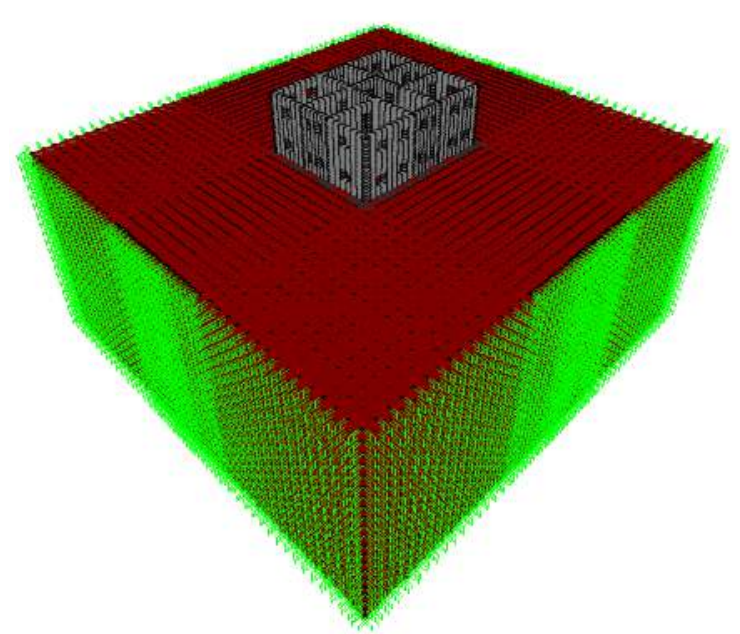

c) Model 3 (Sand soil)

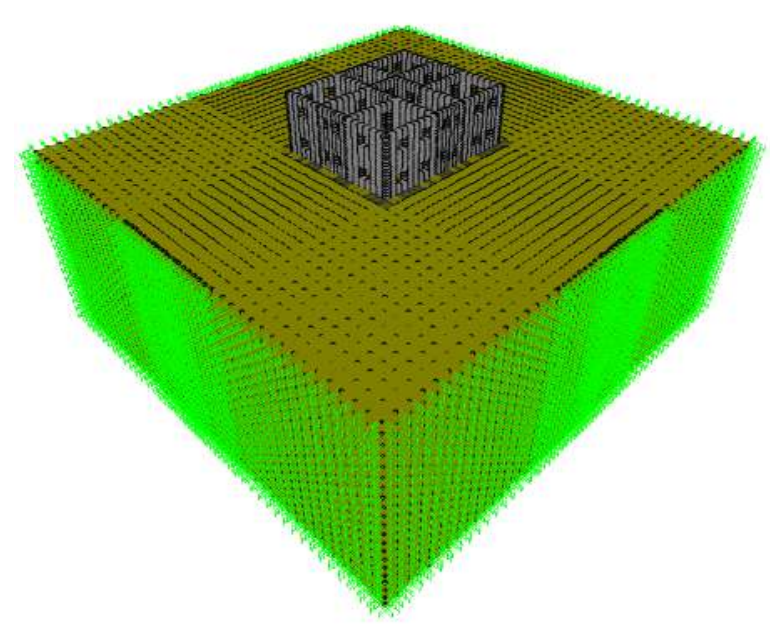

b) Model 2 (Rock soil)

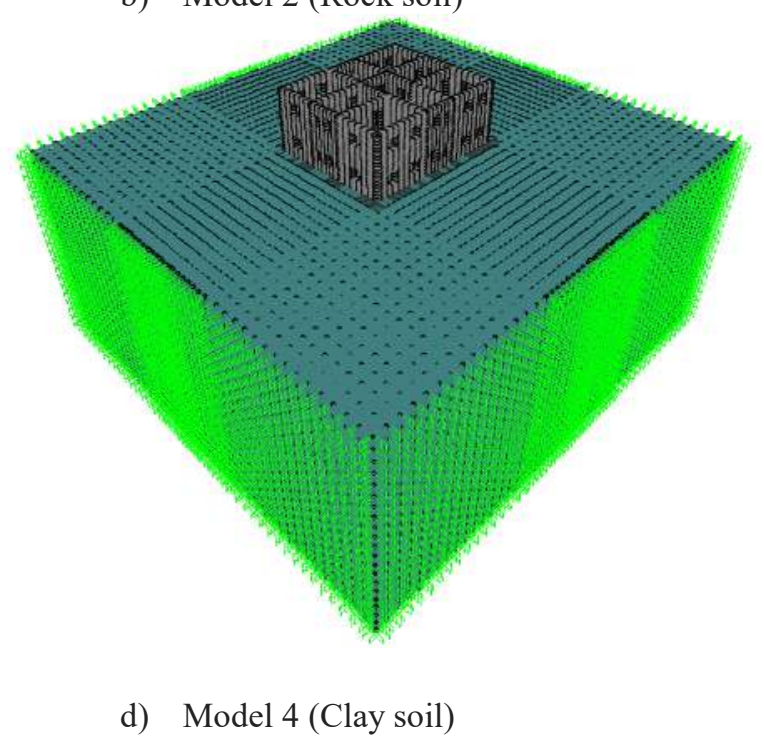


Figure 2. The views of the masonry structure and soils

In order to examine the behavior of the masonry buildings and the soils under the earthquake effect, dynamic analysis are realized. In the dynamic analysis, the time history analysis are used by applyingKobe earthquake.

The properties of the Kobe earthquake applied to the soil-structure models are shown in Table 3 and the acceleration time graphics of the Kobe earthquake is available in Figure1. The displacement and stress values of masonry structure and soil were obtained by using Kobe ground motion data.

Table 3. The properties of the Kobe earthquake used in the analysis

\begin{tabular}{cccccccc} 
Earthquake & Date & $\begin{array}{c}\text { Moment } \\
\text { Magnitude }\left(\mathbf{M}_{\mathbf{w}}\right)\end{array}$ & Record & $\begin{array}{c}\text { Ground } \\
\text { Velocity } \\
(\mathbf{c m} / \mathbf{s})\end{array}$ & $\begin{array}{c}\text { Ground } \\
\text { Acceleration } \\
\mathbf{( g )}\end{array}$ & $\begin{array}{c}\text { Epicenter } \\
\text { Distance } \\
(\mathbf{k m})\end{array}$ & $\begin{array}{c}\text { Type } \\
(\mathbf{k m})\end{array}$ \\
\hline Kobe & 16.01 .1995 & 6.9 & KJM000 & 79.3 & 0.8213 & 6.9 & $\begin{array}{c}\text { Lateral } \\
\text { Slip }\end{array}$ \\
\hline
\end{tabular}

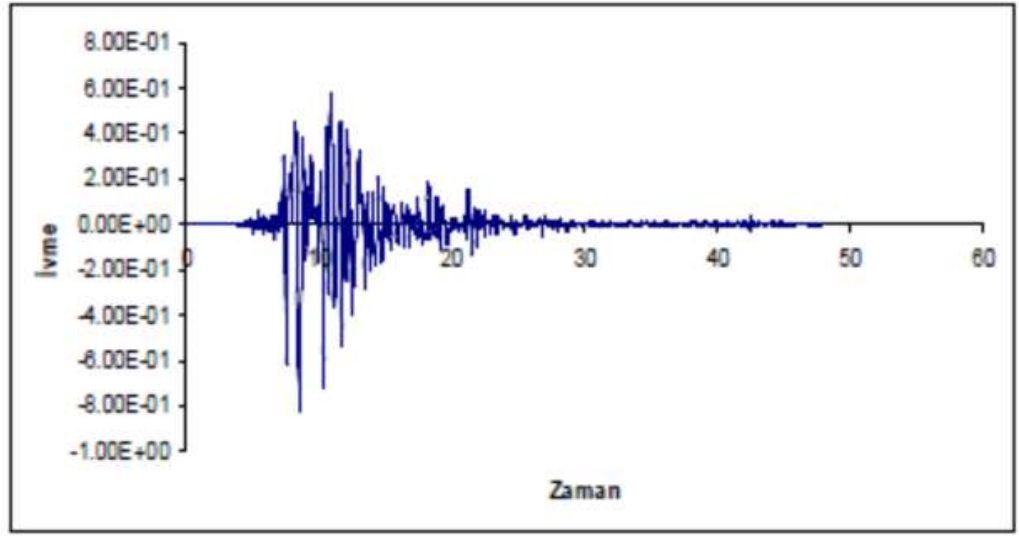

Figure 3. The acceleration-time graph of 1995 Kobe earthquake

\section{Discussion}

In this study, the masonry structure and soil profiles were modeled with finite element method and the dynamic analysis was carried out using the acceleration values of the Kobe earthquake depending on time. As a result of the analysis, period, displacement, and stress values were obtained by using time history analysis method. Moreover, these values were compared for the different soil conditions. The period, stress and displacement values obtained are shown in Figure 4,5 , and 6 , respectively. Since the values of $\mathrm{X}$ and $\mathrm{Y}$ direction are closely similar to each other, 
the displacement and stress values of $\mathrm{X}$-direction are only given.

The values of $\mathrm{X}$-direction displacement and stress were given because the analysis results in $\mathrm{X}$ and $\mathrm{y}$-direction are quite near.

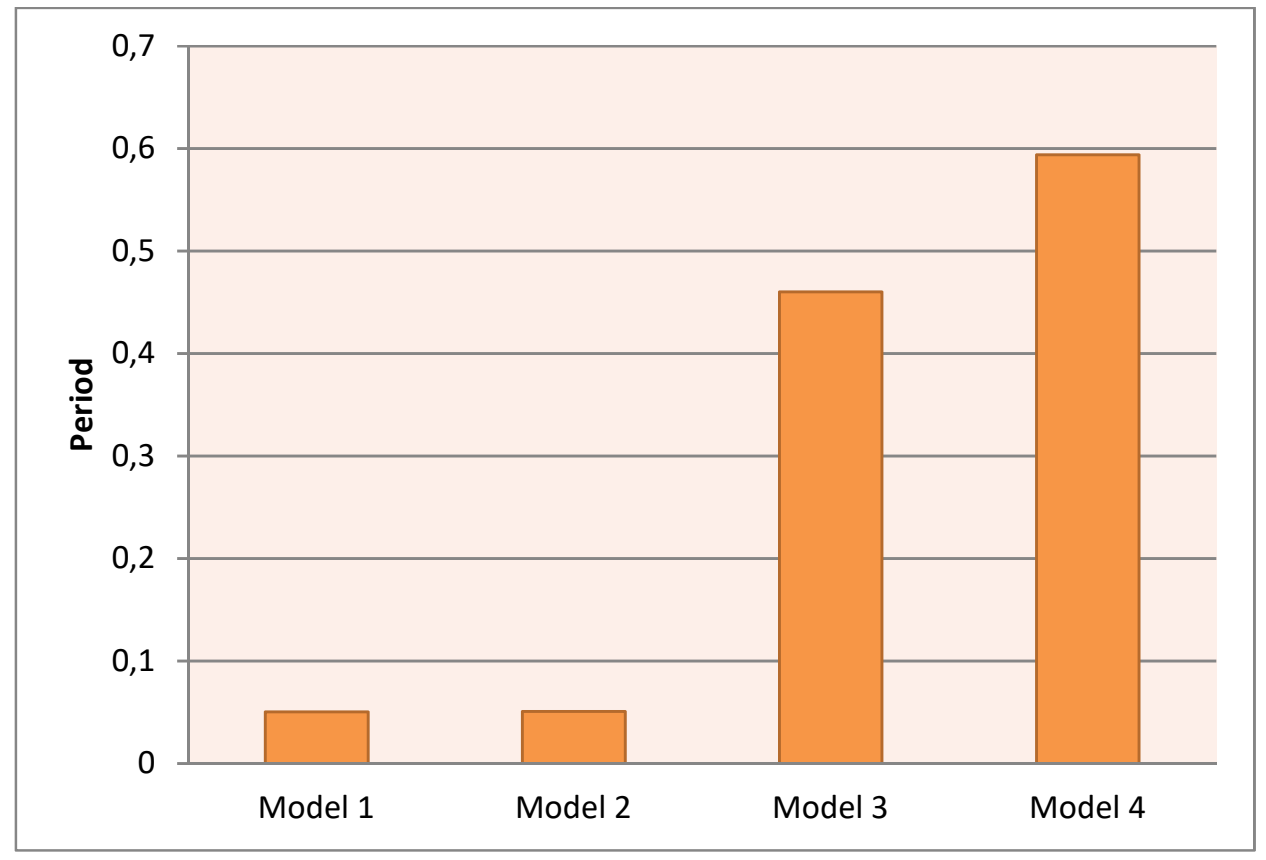

Figure 4. The values of period 


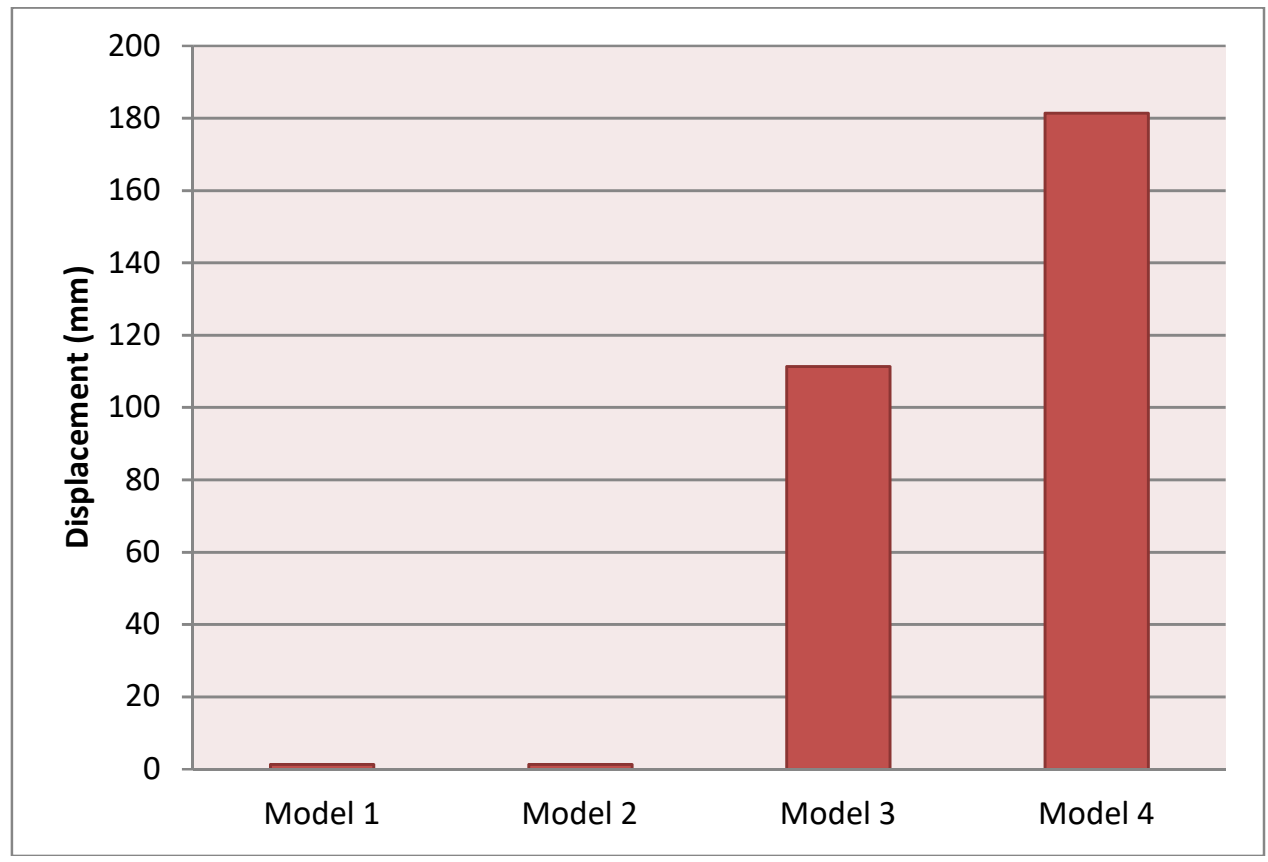

Figure 5. The values of $X$ direction displacement

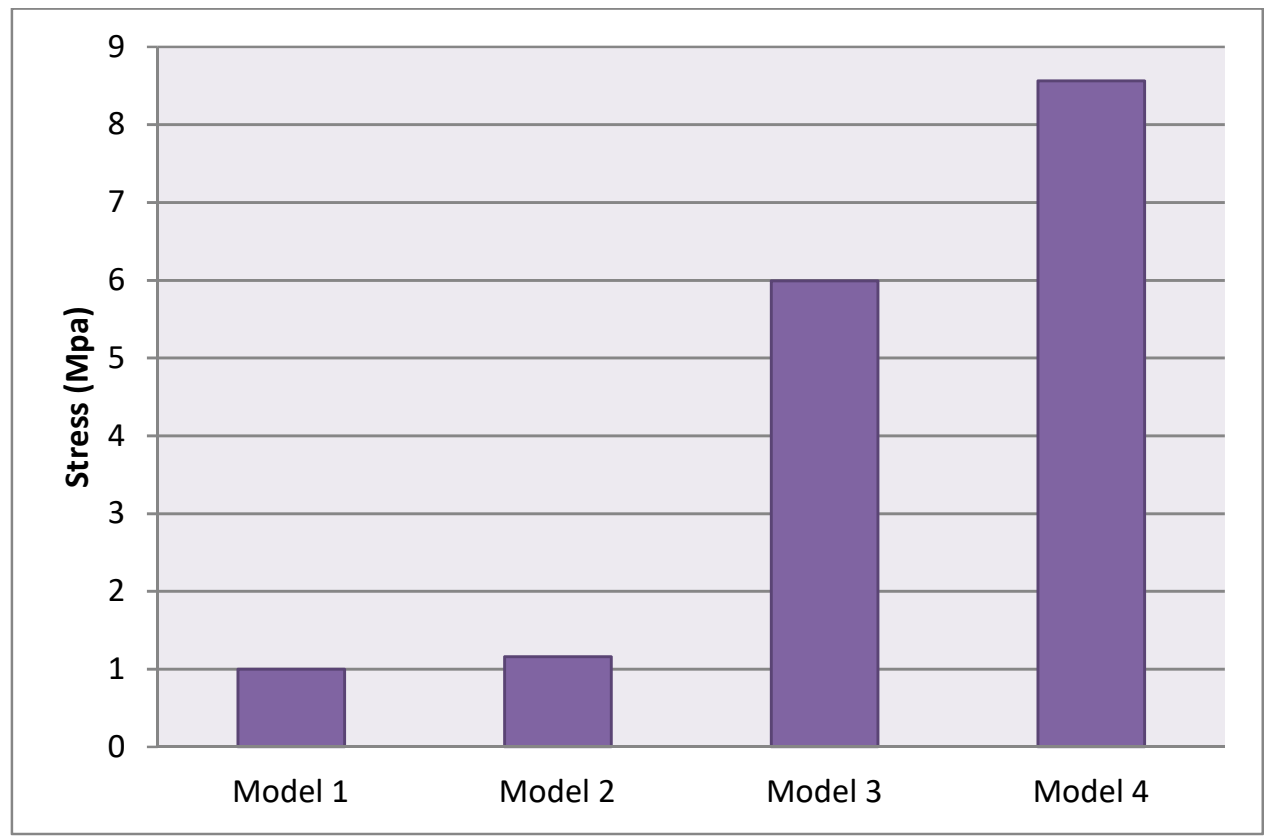

Figure 6. The value of X-direction stresses

\section{Conclusions}


In this study, the behavior of the masonry structure and soil systems, which have different material properties under the earthquake effect, were examined. The dynamic analysis was performed for the purpose of examining the soil-structure interaction It is seen that the properties of the soils play an important role in the structure behaviour during the earthquake.

It follows from the results obtained that the properties of soil material play an important role in the behavior of the structure during an earthquake.

The period values at the clay soil situation is 0.594 and this value is bigger than sand soil. The value period of rock soil and fixed support are is same and smaller than clay and sand soils. The biggest displacement and stress value is occurred on clay soil. When the soil is sand, the displacement and stress values are smaller than the clay soil values. While the displacement and stress values of fixed support and rock soil were obtained very close, the values of clay soil were obtained bigger than the sand soil values. As the stiffness of the structure decreases, the values of the period, displacement, and stress values increase.

\section{References}

[1] Kausel, E. (2010). Early history of soil-structure interaction. Soil Dynamics and Earthquake Engineering, 30(9), 822-832.

[2] Wang, H. F., Lou, M. L., Chen, X., \&Zhai, Y. M. (2013). Structure-soil-structure interaction between underground structure and ground structure. Soil Dynamics and Earthquake Engineering, 54, 31-38.

[3] Wolf, J. P. (1985). Dynamic SoilStructure Interaction. PrenticeHall. Inc., Englewood Cliffs, New Jersey.

[4] Karabörk, $\quad$ T., $\quad$ \&Doğuş, $\quad$ S. $\quad$ (2005). $\quad$ Zemin özelliklerininçokkatlıyapılarındinamikdavranışıüzerineetkisi. DepremSempozyumu, Kocaeli, 1108-1113.

[5] Sica, S., \&Pecce, M. R. (2013). Soil structure interaction on the dynamic behavior of two historic masonry structures. In 2nd International Symposium on Geotechnical Engineering for the Preservation of Monuments and Historic Sites; Napoli; Italy (pp. 657-667). CRC Press/Balkema.

[6] Oyguç, R. A. (2017). 2011 Van depremlerindensonrayı̆̆mayapılardagözlemlenenhasarlar. BalıkesirÜniversitesi Fen BilimleriEnstitüsüDergisi, 19(2), 296-315.

[7] Garip Z.Ş. (2005). Depremetkisindekibetonarmeyapılardayapızeminetkileşimi, YüksekLisansTezi, SAÜ Fen BilimleriEnstitüsü, Sakarya, Ocak.

[8] Pampal, S. (2000). Depremler', Alfa BasımYayımDağıtım, İstanbul, Ocak.

[9] Garip Z. Ş. (2017). Yumuşak Kat DüzensizliğiolanBetonarmeBinalardaYapı Zemin Etkileşimi, 5th International Symposium on Innovative Technologies in Engineering and 
Science, 29-30 September.

[10]Kutanis, M. (2001). Yapı-Zemin DinamikEtkileşimi, DoktaraTezi, SAÜ FBE, Sakarya, Kasim.

[11] Kramer, S. L. (2003). GeoteknikDepremMühendisliği, Ankara ÜniversitesiMühendislikFakültesi,Fersa Matbaacılık,Ankara,s.321-334.

[12] Karabörk, $\quad$ T. (2009). Yapi-Zemin EtkileşimiDikkateAlınarakBetonarmeYapılarınDoğrusalOlmayan 3 BoyutluDinamikAnalizi. YapıTeknolojileriElektronikDergisi, 5(1), 25-36.

[13] Lysmer, J., \&Kuhlemeyer, R. L. (1969). Finite dynamic model for infinite media. Journal of the Engineering Mechanics Division, 95(4), 859-878.

[14] Lou, M., Wang, H., Chen, X., \&Zhai, Y. (2011). Structure-soil-structure interaction: Literature review. Soil Dynamics and Earthquake Engineering, 31(12), 1724-1731.

[15] Elmas M., Kutanis M., 'Yerhareketietkisindekizeminyapısistemlerininüçboyutlusonluelemanlarlamodellenerekincele nmesi.' SAÜ Fen BilimleriEnstitüsüDergisi. 1, 41-47.

[16] Gaikwad, M. V., Ghogare, R. B., \&Vageesha, S. M. (2015). Finite element analysis of frame with soil structure interaction. Int. J. of Research in Engineering and Technology, 4(1), 91-94.

[17] Karaca, Z., Kasimzade, A. A., \& Ak, M. (2007). Zemin fizikselparametreleriilezeminyatakkatsayılarıarasındakibağlantıvezeminyapıetkileşimindeuygulama. Zemin MekaniğiveTemelMühendisliği, 1.

[18] Vicencio, F., \& Alexander, N. A. (2018). Dynamic interaction between adjacent buildings through nonlinear soil during earthquakes. Soil Dynamics and Earthquake Engineering, 108, 130-141.

[19] Pacific Earthquake Engineering Research (PEER) Center, PEER Strong Motion Database., http://peer.berkeley.edu

[20]Wilson, E. ve Habibullah A., (1998). 'SAP 2000 Integrated Finite Element Analysis and Design of Structures Basic Analysis. 